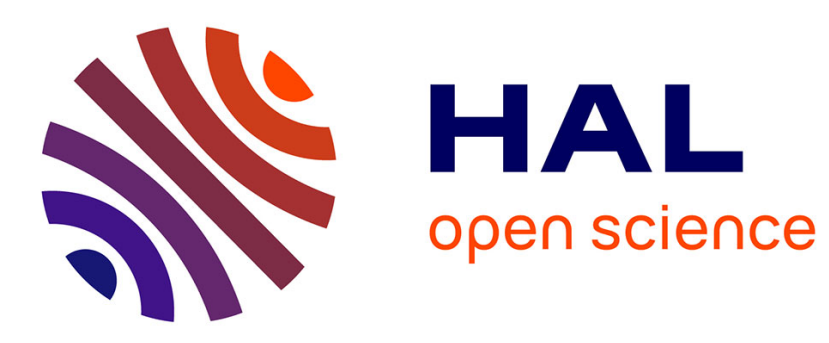

\title{
Better understanding EMI generation of power converters
}

Piotr Musznicki, Jean-Luc Schanen, Pierre Granjon, Piotr Chrzan

\section{To cite this version:}

Piotr Musznicki, Jean-Luc Schanen, Pierre Granjon, Piotr Chrzan. Better understanding EMI generation of power converters. 36th IEEE International Power Electronics Specialists Conference (PESC 2005)., 2005, Recife, Brazil. hal-00021518

\section{HAL Id: hal-00021518 https://hal.science/hal-00021518}

Submitted on 22 Mar 2006

HAL is a multi-disciplinary open access archive for the deposit and dissemination of scientific research documents, whether they are published or not. The documents may come from teaching and research institutions in France or abroad, or from public or private research centers.
L'archive ouverte pluridisciplinaire $\mathbf{H A L}$, est destinée au dépôt et à la diffusion de documents scientifiques de niveau recherche, publiés ou non, émanant des établissements d'enseignement et de recherche français ou étrangers, des laboratoires publics ou privés. 


\section{Better understanding EMI generation of power converters}

Piotr Musznicki ${ }^{1}$

\author{
Jean-Luc Schanen ${ }^{2}$ \\ senior member IEEE
}

Pierre Granjon $^{3}$

Piotr Chrzan ${ }^{1}$

1. Politechnika Gdanska,

Wydział Electrotechniki i Automatyki KeiME, ul Sobieskiego 7, 80-216 Gdansk pmusz@ely.pg.gda.pl

2. Laboratoire d'Electrotechnique de Grenoble,

UMR 5529 INPG/UJF - CNRS, ENSIEG - BP 46 - 38402 Saint-Martin-d'Hères Cedex jean-luc.schanen@leg.ensieg.inpg.fr

3. Laboratoire des Images et des Signaux (LIS),

INPG, BP46, 38402 St Martin d'Hères, France pierre.granjon@lis.inpg.fr

\begin{abstract}
This paper describes how the use of a specific signal processing method can help understanding the EMI generation of a switched mode power supply. It provides an equivalent system between a supposed disturbance source and the actual EMI signal. To identify this system, the "Wiener filtering" method is applied. Both experimental and simulation waveforms may be used. This method is illustrated in the simple example of a boost switching cell. The application to more complicated power electronics structures with several switches is also possible.
\end{abstract}

\section{INTRODUCTION}

It is well known that switching phenomena in power electronics converters are at the origin of EMI (Electromagnetic Interference) generation. The reduction of this emission to meet the international standards necessitates understanding EMI generation and propagation process. Several authors have tried to investigate this aspect, using various experiments and/or simulations [1], [2], [3]. The "new way" of fast EMI predicting method, which allows a fast and more accurate estimation of the EMI/EMC effects of a power electronic application, is presented. The method presented here starts from digital signal processing basis, and tries to determine the contribution to perturbations level, due to switch turn on and turn off. This DSP method is based on powerful Wiener filtering approach [4], which links the source of disturbances and noise measured on LISN.

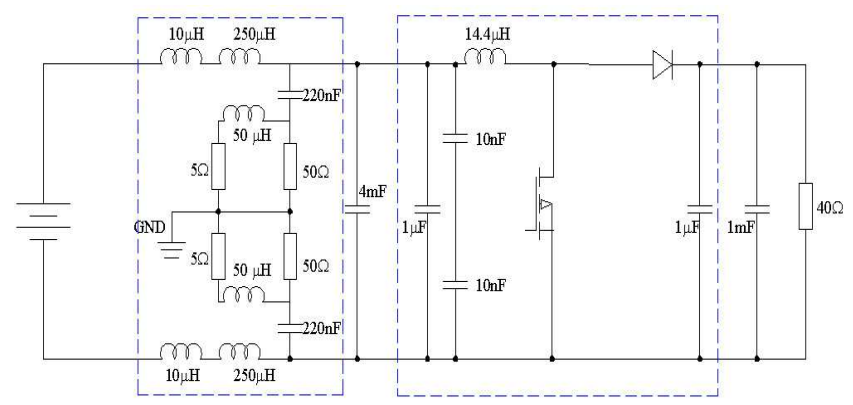

Fig. 1: The chosen for study DC-DC $14 \mathrm{~V}-42 \mathrm{~V}$ boost converter . of Power Electronic system. This method is illustrated in this paper on the simple example of a boost converter (fig. 1), where two main propagation paths can be defined due to semiconductors states: the first when MOEFET is on and diode is off, the second - reverse. In order to reconstruct disturbances waveform, Wiener filters are calculated for each state.

In this method, EMI behavior of boost is represented by the system which contains transfer functions between semiconductor devices and perturbations. It allows finding the role of the disturbance source (MOSFET, diode) on the global EMI generation and propagation.

First, the theoretical development of the method will be briefly detailed (section II). Then, the validation and comparison with other methods of EMI level prediction in frequencies domain will be presented (section III). Section IV contains reconstructions of perturbations waveforms obtained with measurements and temporal simulations. Discussion and propositions of applications can be found in section V.

\section{WIENER FILTER IN EMI PREDICTING - THEORY}

The main assumptions of this method are as follows:

- the system represented by one Wiener filter is linear and time-invariant,

- noise from other sources is not correlated with the main signals.

In order to find transfer function of the system, at least two signals are needed - input signal (source of disturbances) and output signal (disturbances measured).

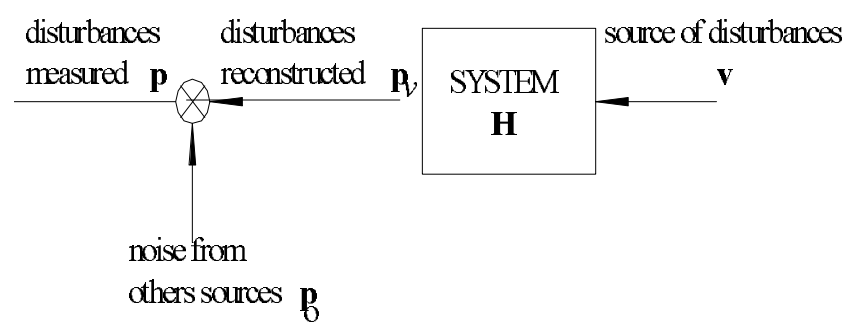

Fig. 2: Wiener filter theory. 
It is known that signals from source (v) and disturbances measured (p) are correlated; moreover there is no correlation between signal from source and others noises. In the frequency domain, the Wiener filter output $X(f)$ is the product of the input signal $\mathrm{Y}(\mathrm{f})$ and the filter frequency response $\mathrm{W}(\mathrm{f})$ :

$$
P_{V}(f)=H(f) V(f)
$$

It can be proved that transfer function of the system could be obtained using the power spectrum of $p(\tau)$ (equation 2a), and the cross-power spectrum of $p(\tau)$ and $p(\tau)$ respectively (equation $2 b$ ) [9]. The least mean square error Wiener filter in the frequency domain is given as:

$$
H(f)=\frac{S_{v p}(f)}{S_{v}(f)}
$$

where:

$$
\begin{aligned}
& S_{v p}(f)=E\left[V(f) V^{*}(f)\right] \\
& S_{v p}(f)=E\left[P(f) V^{*}(f)\right]
\end{aligned}
$$

Link between input and output signals can be also found in time domain by defining impulse response of the system $\mathrm{H}$ and convolution of $v(t)$ and $p(t)$.

Because phenomena during switching and EMI generating in Power Electronic applications are no linear, we decided to compose the system with two linear filters for two states. It should be noticed that this two single states includes also the transient state of the switch.

The complete EMI generation has been identified by the assembly of different filters. The disturbance source is the MOSFET voltage $V_{d s}$, and the gate signal $V_{g s}$ will be used to give the state of the system (fig. 3).

The new approach is based on 3 step calculation and has been implemented in Matlab ${ }^{\circledR}$ software:

- in the first step all signals are separated into two groups, one for on state and one for off state. The detection of the "cutting times" uses $\mathrm{V}_{\mathrm{gg}}$ or its derivative. A threshold is defined, which must allow a correct separation of the different states,

- two independent linear systems are identified in the second step - the first one for the on state and the second one for the off state of switch. In this procedure as an input references signal $V_{\mathrm{ds}}$ can be apply, but (for physical aspect) it is better to use $\mathrm{dV}_{\mathrm{ds}} / \mathrm{dt}$,

- perturbations generated are reconstructed in the third step. Two systems are used to reconstruct the electromagnetic perturbations generated by the boost in both states of the switch. Next, obtained signals are summed to find all perturbations in time domain.

Several signals have been investigated: the LISN voltages are the global consequence of the converter EMI. The different origin may be:
- MOSFET power voltage

- MOSFET gate signal

- MOSFET current

- diode voltage

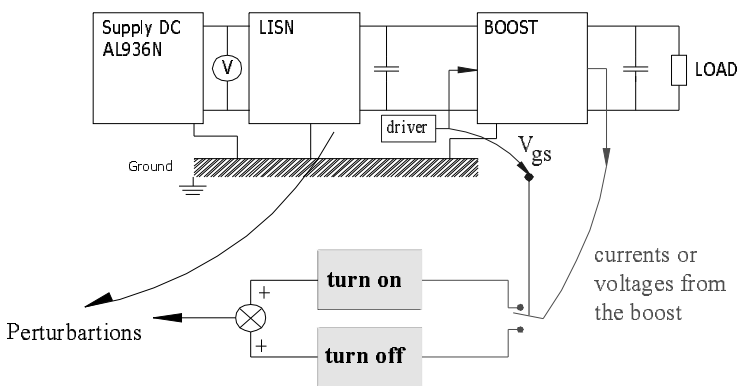

Fig. 3: Two different systems for each state of the MOSFET.

- diode current.

It is important to use sufficient number of boost working periods with a sufficient sample number, according to Nyquist rule [9], in order to find signals average power spectra and to reconstruct them in the frequency range of the conducted emission standard $(10 \mathrm{kHz}-30 \mathrm{Mhz})$

\section{APPLICATION IN FREQUENCY DOMAIN}

In order analyse the boost behaviour in the frequency range of the conducted EMI, transfer function between the source of disturbances $\left(\mathrm{V}_{\mathrm{ds}}\right)$ and disturbances $\left(\mathrm{V}_{\mathrm{LISN}}\right)$ has been identified using three different approaches numerical simulations, simply analytical calculation and signal processing. Accurate ac analysis simulations have been done with Saber, where apart from all primary components, all parasitic elements have been taken in to consideration [5]. Two transfer functions have been computed: The one corresponding to MOSFET on state replaces the diode with its stray capacitor and the MOSFET with its $R_{d s o n}$. The one for the off state replaces the MOSFET with its parasitic capacitor $\mathrm{C}_{\mathrm{oss}}$, and the diode with a low on state resistor. On figure 4, comparison of

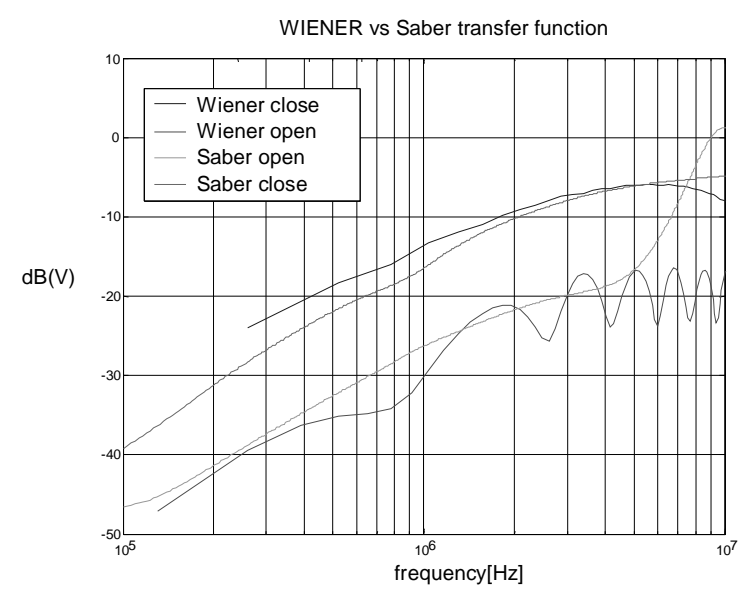

Fig. 4: Transfer functions identify with numerical simulations and Wiener filters 
transfer functions (TF) obtained with Saber (ac analyses) and Wiener filter are presented. It can be noticed that in range $50 \mathrm{kHz}-10 \mathrm{MHz}$, the levels and envelopes for each state are similar, the differences begin in the high frequencies range, due to fact that Saber simulation don't take in to account transient phenomena, so the states of semiconductors are not exactly the same for these two approaches. Moreover, transfer function of Wiener filters is sensitive to the dividing moment (threshold level). In spite of it, it is interesting to see that there is almost $10 \mathrm{~dB}$ different between open and close state. The two propagations path for EMI are thus different..

In analytical way - the MOSFET and the diode have been replaced with a simple voltage source, and no inductive parameters have been taken into account for interconnects (fig. 5). Additionally, all capacitive aspects have been kept in the modelling. Two main parasitic capacitances, due to the layout are also taken into account [7]. This leads to a very light linear model, and therefore to fast and easy calculations.

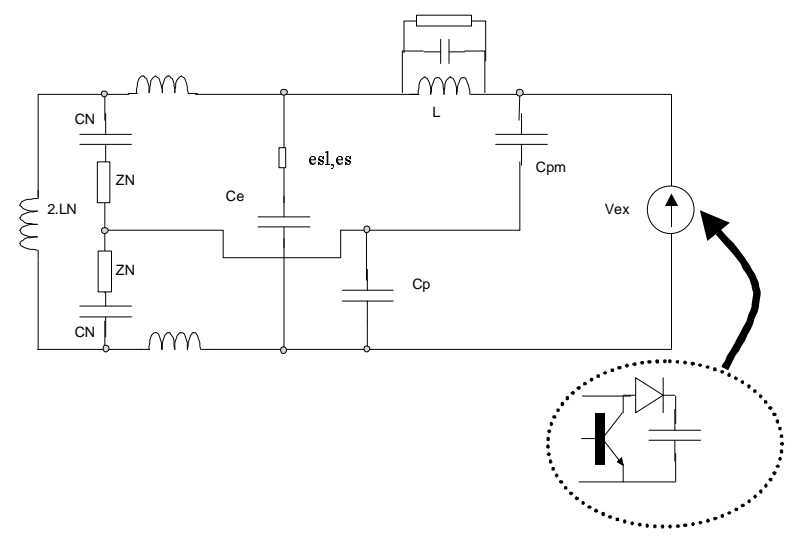

Fig. 5: Simplified analytical model

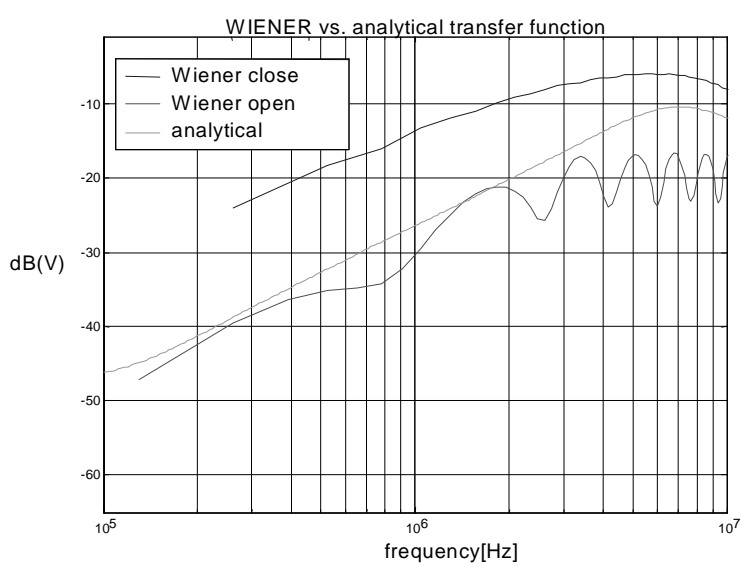

Fig. 6: Transfer functions from analytical model and Wiener filters

On figure 6, Wiener filter's transfer function is presented in comparison with one obtained with analytical model. This transfer function is located between open and close states transfer functions, what seems normal since it accounts for both states.

This section has shown that using a filtering method, it is possible to identify transfer functions linking the voltage across the MOSFET to the voltage across LISN. Two different transfer functions have been identified, one for the on state, one for the off state. The great interest of this method is that it does not necessitate any knowledge of the converter structure. It is an identification process, which considers the converter as two "black boxes". This method has been compared successfully with SABER AC analysis, using very precise model of the converter for each state of the MOSFET. A simpler analytical model, used in past works has also been compared to this method. Obviously it is less precise, but the order of magnitude is respected.

\section{RECONSTRUCTION OF DISTURBANCES TEMPORAL WAVEFORMS}

After the identification of the two systems corresponding to the boost, it is possible to reconstruct the EMC disturbances. On Fig. 7 are presented voltages registered on LISN obtained with Saber time simulations in comparison with reconstructed signal, using the two Wiener filters. As

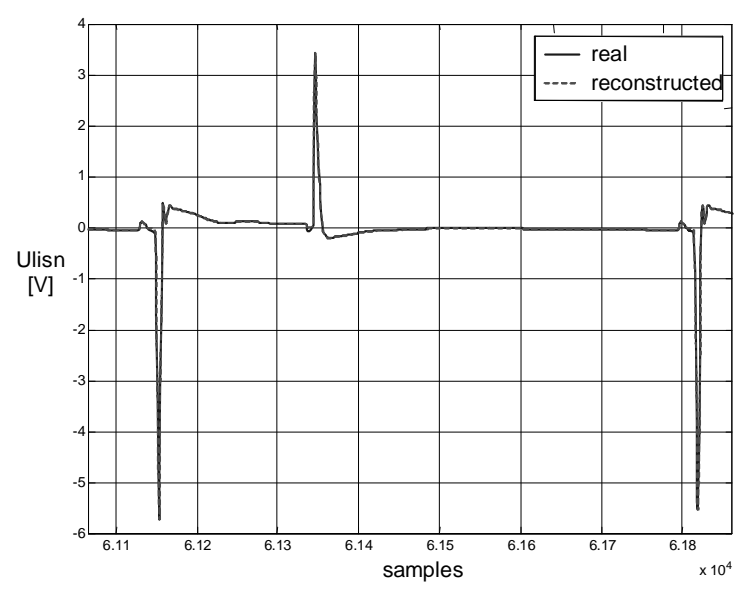

Fig. 7: $\mathrm{U}_{\text {LSN }}$ simulated witch Saber ${ }^{\circledR}$ and reconstructed by Wiener filter.

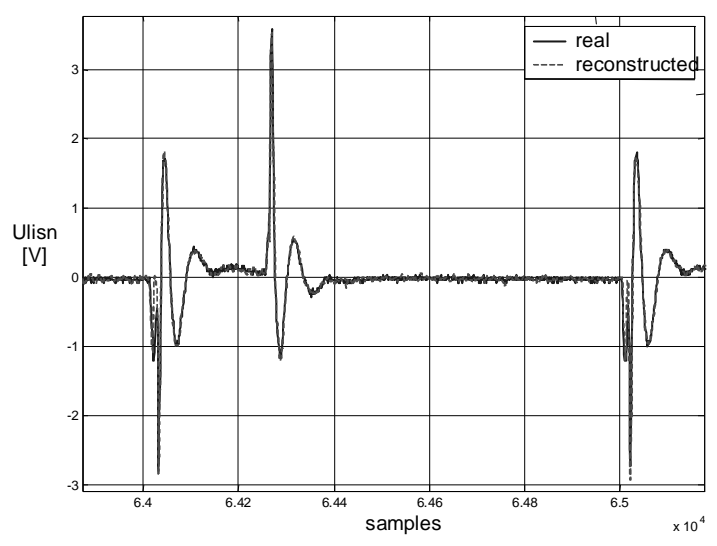

Fig. 8: $\mathrm{U}_{\text {LISN }}$ measured and reconstructed by Wiener filter - one period 
an input signal, MOSFET voltage $\mathrm{V}_{\mathrm{ds}}$ has been used.

Other semiconductors waveforms may have been used for identification and reconstruction. However, measurement of the voltage across MOSFET was the most simple (compared to current mesurement for instance).

Signals in the time domain used to obtain Wiener filters, have been obtained with either accurate numerical simulations or measurements on the real object. The precise SABER simulations, taking into account all stray elements has been carried out, in order to test the validity of the method with simulated signals. Simulation is especially interesting since all signals are available. The drawback is the semiconductor model accuracy and the difficulty to reach the steady sate, with the large time constants of the LISN [2], [5]. For measurements, only voltages were available (no current sensor in the converter). A four channel oscilloscope was used. The signals have been

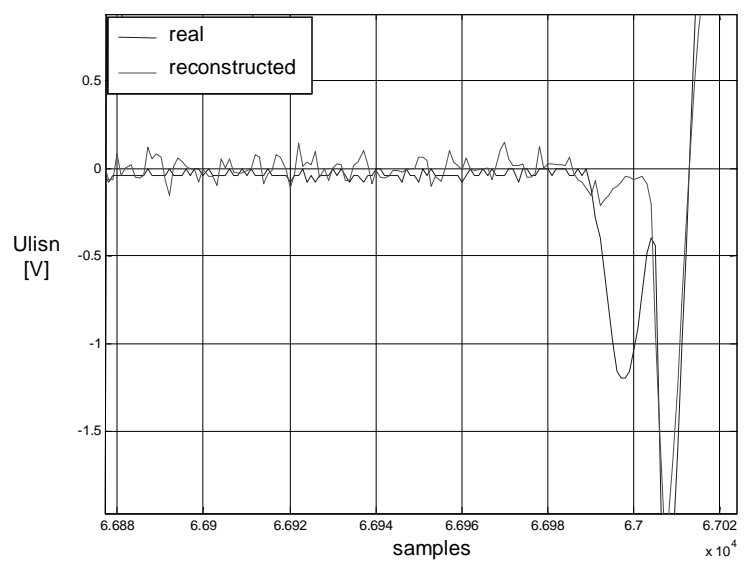

Fig. 9b: $\mathrm{U}_{\text {LISN }}$ during commutation measured and reconstructed by Wiener filter - separating of driver contribution.

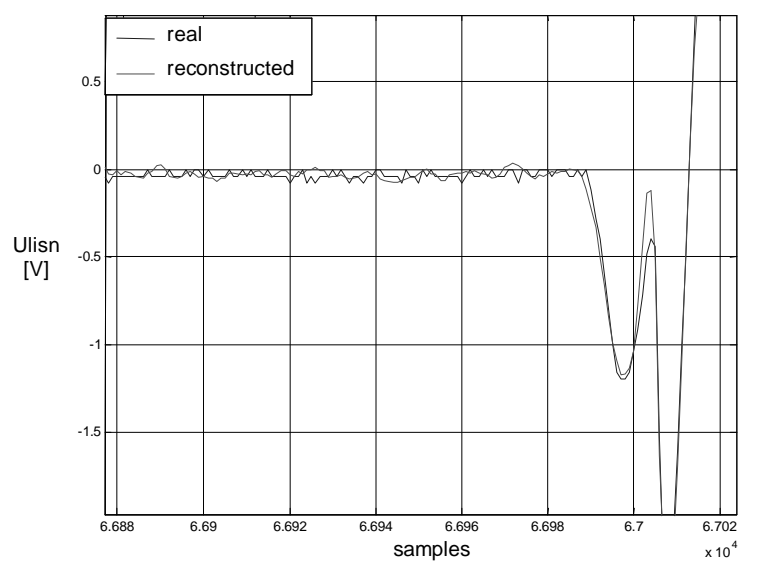

Fig. 9a: $\mathrm{U}_{\text {LISN }}$ during commutation measured and reconstructed by Wiener filter - reconstruction of driver contribution. divided on "open state" part and "close state" part using $\mathrm{V}_{\mathrm{gs}}$ gate-source voltage. It is possible to choose a moment of signal dividing by setting up suitable threshold.

Figures 7 and 8 show how the LISN voltage is reconstructed with satisfying accuracy. All signals on figures are normalized (mean value is zero) and presented as a function of sample number. However, having a more precise look on this signal shows a little difference, at the beginning of the switching process. This difference may be attributed to the driver commutation, which swings from $0 \mathrm{~V}$ to $15 \mathrm{~V}$ within approximately the same time as the power signal $(0$ to $42 \mathrm{~V})$. In fact, it is another disturbance source in the converter.

In order to reconstruct measured perturbation, $\mathrm{dV}_{\mathrm{ds}} / \mathrm{dt}$ signal have been used as reference input signal. Results are presented on fig 8 . It can be noticed that noises that appear in during measurement are not reconstructed (Fig. $9 \mathrm{a}, \mathrm{b}$ ), since they are not correlated with source of disturbances $\mathrm{V}_{\mathrm{ds}}$. Thanks to the Wiener filtering method, it is possible to separate the contribution of the driver from the one of the power part by choosing different threshold in dividing process, so driver contribution can be reconstructed (Fig. 9a) or not (Fig. 9b). Indeed, the peak before commutation in simulated (or measured) disturbance is not reconstructed, since it does not depend linearly on $\mathrm{V}_{\mathrm{ds}}$. Moreover, it is possible to divide perturbations in the groups for different converter state and propagations path - on figure 10 open state and close state perturbations are separated. If chosen threshold is too high some perturbation from one state could be signed to the second one. It can be reason of differences between impulse responses and transfer
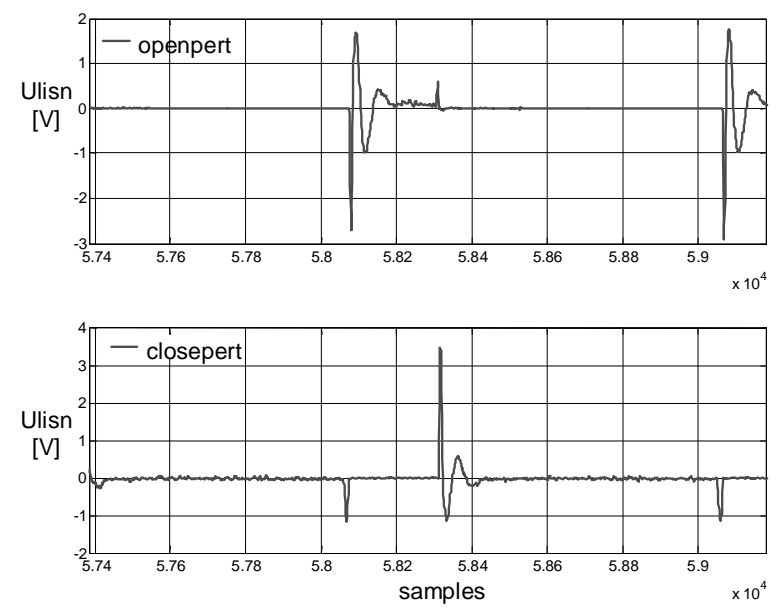

functions obtained wit others method and one identified by the Wiener filter (Fig. 4 in section III), but it has no influence on reconstruction process in time domain.

\section{CONCLUSION}

A "Wiener filtering" method has been presented to 
determine the main cause of EMI disturbance, originated from a power electronics converter. This temporal and frequency methods can use either measurement signals or simulations. It has been applied to a boost switching cell, where power MOSFET voltage is shown as the main EMC actor and reconstructions works quite good and fast.

The "Wiener filter" method in Power Electronic applications such as DC-DC boost converter can be used to reconstruct generated perturbations and find out the links between then and sources of them. Transfer functions or impulse response can be defined in order to describe EMI behavior for different states of switches and propagations paths.

Once the different transfer functions are known, it is possible to change the shape of sources waveforms (voltages or current of semiconductors), to check how it influences the perturbations shape and level. For instance, soft switching may be investigated very quickly. Another interesting application should be to study the influence of the driver in hard switching process. For instance, the role of gate resistor in simple drivers can be easily underlined. Additionally, the effectiveness of some known solutions [8] may thus be immediately checked. Therefore, Wiener filter can be a powerful tool during the design process.

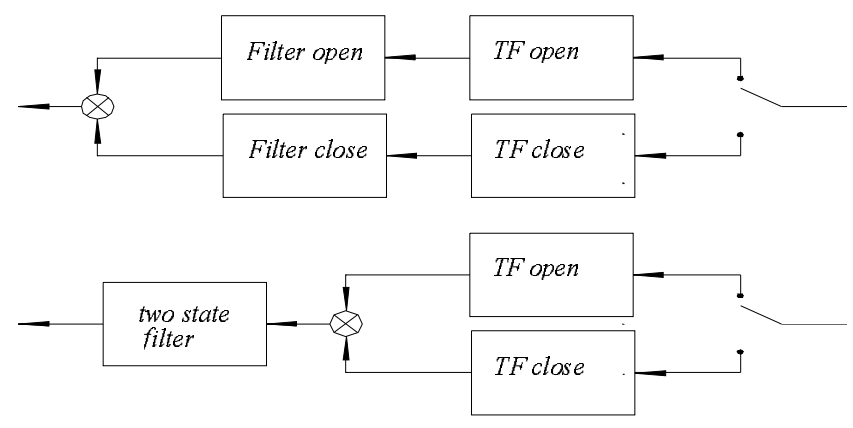

Fig. 11 Filter synthesis

Another interesting idea may be validated in the EMC filter design. In order to reach the perturbation level restricted by EMI standards, suitable filter should be applied. Using this method, it is possible to investigate the influence of the different type of filters on generated perturbation. A better knowledge of EMC generation mechanisms would allow a better filter synthesis. After obtaining an "optimal" filter for each state, it may be studied how to combine them into a single structure. (Fig. 10). This approach will be perhaps presented in future work.

\section{REFERENCES}

[1] F.Costa, E.Laboure, F.Forest, S.Lefebvre "Quantification and minimization of conducted interferences generated in hard switching and zero current switching cell", APEC'94, 13-17 Feb 94.

[2] P.Musznicki, JL.Schanen, B.Allard, P.Chrzan "Accurate modeling of layout parasitic to forecast EMI emitted from a DC-DC converter", PESC 04, Aachen, Germany
[3] L Rossetto, G.Spiazzi, P Tenti "Boost PFC with $100 \mathrm{~Hz}$ switching frequency providing output voltage stabilization and compliance with EMC standards", IEEE trans on IAS, Vol $36 \mathrm{n}^{\circ} 1$, Jan-Feb 2000

[4] B. Widrow et al., "Adaptive noise cancelling: principle and applications", IEEE Proceedings, Vol 63, Dec. 1975, pp. 1692-1716.

[5] B.Revol, J.Roudet, J.Schanen, P.Loizelet "EMI study of a three phase inverter-Fed Motor Drives", IAS 04, Seattle, October 2004

[6] JC.Crébier, J.Roudet, J.L.Schanen, "EMI analysis of single phase PFC boost rectifier in the frequency domain", Revue Internationale de Génie Electrique, Vol2 n² 1999, pp 215-241.

[7] JL.Schanen, L.Jourdan, J.Roudet "Layout optimization to reduce EMI of a SMPS", Pesc 2002, Cairns, Queensland, Australia.

[8] F. Costa, E. Laboure, F. Wilmot, F. Forest (Lesir), F. Reby, R. Bausiere, C. Rombaut, An innovative gate drive to control electromagnetic perturbations emitted by a Mosfet chopper" EPE'99, Lausanne, Suisse, September 1999.

[9] S. V. Vaseghi "Advance digital signal processing and noise reduction" 2000 John Wiley \& Sons Ltd 